\title{
ВОСПРИЯТИЕ МОСКВИЧАМИ БОЛЬШЕВИСТСКОЙ ВЛАСТИ В ГОДЫ ВОЕННОГО КОММУНИЗМА
}

\section{PERCEPTION OF THE BOLSHEVIK REGIME BY MOSCOW CITIZENS DURING THE YEARS OF THE WAR COMMUNISM \\ K. Morgunov}

Summary: The problem of the first years of the Bolshevik rule in Moscow is being studied today from different angles. An approach in which the main actors are ordinary people, and the focus of the study is their subjective interpretation of the processes that took place in the past, has received a wide representation in historical science nowadays. This article is an attempt to demonstrate how Moscow citizens perceived the power of the Bolsheviks during the Civil War. This perception was complex and ambiguous, and often citizens tried to simply adapt to the new social reality.

Keywords: Moscow, Moscow citizens, everyday life, Civil war, Bolsheviks, power.

\author{
Моргунов Кирилл Геннадьевич \\ Аспирант, Московский городской \\ педагогический университет \\ jacuzzifiend@gmail.com
}

Аннотация: Проблема первых лет правления большевиков в Москве изучается сегодня под разными углами. Широкое представление в исторической науке получил подход, в котором главными акторами являются простые люди, а в фокусе исследования - их субъективная интерпретация процессов, происходивших в прошлом. Данная статья - попытка продемонстрировать как воспринимали москвичи власть большевиков в годы Гражданской войны. Восприятие это было сложным и неоднозначным, а зачастую москвичи и вовсе старались просто адаптироваться к новой социальной реальности.

Ключевые слова: Москва, москвичи, повседневность, Гражданская война, большевики, власть.
$\mathrm{B}$ данной статье речь пойдёт не о власти большевиков как таковой, а об её восприятии горожанами. Москва, с рядом оговорок, стала одним из городов, в котором партия В.И. Ленина прижилась достаточно быстро. После «октябрьской недели» боев в 1917 году - дальнейшие будни (особенно если говорить про 19191921 гг.) протекали практически без горячего и политически мотивированного сопротивления большевикам в сравнении с другими местами на карте России. В годы Гражданской войны, в целом намечалась тенденция бегства из крупных городов в сельскую местность. Это было вызвано, в первую очередь, решением продуктового вопроса. Количество жителей в Москве существенно изменилось, с 1916 по 1920 гг. оно сократилось с почти двух до одного миллиона человек [15, с. 10]. Можно предположить, что оставшиеся в городе люди, зачастую, не имели «пути отступления» и были вынуждены адаптироваться к новой социальной реальности, т.к. они существовали непосредственно рядом с вновь созданными властными институтами. Ведь москвичи воспринимали власть большевиков по-разному, однако даже в критических размышлениях или реакциях, они говорили о них именно в контексте властном. Для этого есть несколько причин.

Любая власть - хорошая она или плохая, пытается придумать для себя идею легитимности, опираясь на которую она сможет управлять людьми. И что гораздо важнее - необходимо, чтобы эта идея находила отклик в сердцах рядовых граждан. Для большевиков на первых этапах правления можно выделить сразу несколько таких идей. Взгляды вождей пролетарской революции транслировались, в частности, через печать. Для большевиков одним из главных идеологических рупоров являлась газета «Правда». В выпуске от 12 марта (27 февраля) 1918 г. (условно можно назвать это «начавшейся» годовщиной Февральской революции) мы можем увидеть основную идею, которую большевики постоянно повторяли: «Рабочие, солдаты и крестьяне создали свою власть - Советскую власть» [13, с. 1]. В данном заголовке февраль уже считается за начало социалистической революции. Она представлена в виде каскада событий: сначала свергнуто «царское иго» (которое было лишено народной опоры), затем пала «буржуазная власть Милюкова» и в конце было сброшено «соглашательское правительство Керенского» [13, с. 1]. И уже после всего этого, русский народ добился своей, «правильной власти». Подразумевалось, что это лишь первый этап, ведь в том же заголовке сразу появляется и другая идея: мировая революция не за горами, но есть определённая группа людей в каждой стране, которая мешает этому свершиться (собирательным термином для этой группы было слово «буржуазия»). В виду этого подключалась следующая идея «о кольце врагов-империалистов», а военная риторика, присущая данному периоду в целом, использовалась ещё и в контексте «борьбы за революцию» в частности, в которой «каждый должен сохранять свой пост». Какие выгоды у простого обывателя от всего это- 
го? В первую очередь, это привилегия жить в демократической стране [13, с. 1]. Во вторую - революция способствует превращению страны из отсталой в передовую. Таким образом, общую идею следует охарактеризовать примерно так: власть работает на благо людей, а не наоборот. Обывателям объясняли, почему они сейчас живут хуже, чем раньше в том числе и посредством агитационных материалов. Но за политическими лозунгами стояла и суровая реальность, которую следовало обуздать для удержания самой власти. В первые годы большевики основной упор делали на мобилизационном способе управления и силовых методах решения поставленных задач. В силу отсутствия каких-то адекватных регулятивных механизмов для поддержания социальной стабильности, а также невероятного разгула преступности, причин для которого было более чем достаточно, подавляющее большинство полномочий переходило к «чрезвычайкам». Данный тезис поддерживает исследователь В.А Бондарь, который, в частности, отмечает: «Логичной на данном этапе (военного коммунизма - прим. К.М.) была концентрация полномочий в руках чрезвычайных органов и должностных лиц, которые как минимум разделяли коммунистические идеи» [19, с. 161]. Важно отметить, что отношение к насилию со стороны людей в это время существенно поменялось, примером этого может служить возрастающий рост самосудов в конце 1917 начале 1918 гг. [1, с. 898].

Безусловно следует сделать оговорку, что в новые создававшиеся органы идейных большевиков набрать не было никакой возможности, поэтому «старорежимные» клерки плавно перетекли в различные структуры и вопрос о восприятии большевистской власти на порядок усложняется. Ведь кого мы можем считать большевистской властью? Только первых лиц молодой Советской республики? Однако, как показывает практика, «наделённым властью» считался всякий, у кого было соответствующее удостоверение или внешний вид. Так, в 1919 году член государственного контроля И.Б. Эльяшевич был с ревизией в чайной номер 23 в Замоскворецком районе Москвы и в отчёте написал о неудовлетворительных условиях - повсюду была грязь, а подметать начали, только когда заметили его [17, Л. 27].

С другой стороны, любопытно проследить реакцию на главную властную фигуру - В.И. Ленина. Несмотря на позиционирование партии большевиков как демократической и управляющейся коллективно, от персонализированного восприятия нового режима никуда было не деться и на виду были два главных харизматика «Октября»: В.И. Ленин и Л.Д. Троцкий. У москвича Н. Окунева представители власти и сама власть вызывали вполне конкретные ассоциации. Празднование годовщины Октябрьской революции в 1918 году проводилось с большим размахом. Как писал горожанин, такого салюта Москва не видела со времён коронации Николая II [8, с.
230]. А смотр Красной армии, произведённым Л.Д. Троцким, сидящем на коне, был им охарактеризован так: «поцарски» $[8$, с. 236]. И это не удивительно, ведь москвич встречал революцию уже человеком немолодым, так как в одной из записей он сообщал, что является ровесником последнего русского императора [8, С.203], а также упоминал о своём дне рождении: в сентябре 1918 года ему исполнилось 50 лет [8, с. 220]. Все те базовые установки, которые обеспечивали нужное восприятие мира до революции, теперь помогали интегрировать новые нетипичные образы в сферу типичного. Человек хабитуализирует (опривычывает) пространство, действия и т.п вещи для более комфортного существования. Под данным термином подразумевается конкретный набор социально одобряемых, привычных (т.е всегда работавших до этого) действий, которые помогают человеку существовать в жизненном мире. Кроме того, такое опривычивание и есть во многом институт. В основе любой типизации и лежит процесс хабитуализации, так как именно он закладывает все те предожидания, которые существуют у людей. Каждый возникший институт подразумевает, что деятели типа $X$ должны совершать действия типа $X[3$, с. 92]. Отсюда и рождаются подобные ассоциации в восприятии.

Идея о восприятии власти большевиков как «народной» подвергалась сомнению на старте революционного строительства. Некоторые обыватели как бы предупреждали или даже слегка поучали лидера партии: «Я молод тов. Ленин, но всё-таки мой вам совет: не давайте расти такой стене между вами и пролетариатом» [7, с. 21]. Чуть раньше похожее предостережение появилось на страницах Правды в небольшой заметке «Понять и сказать: Коммунисты начинают отрываться от массы» [9, с.3]. Такие высказывания относятся к 1919-1920 гг. В данном контексте «отрыв» подразумевает плохую информированность о состоянии на местах. Что любопытно - В.И. Ленин для многих пишущих на его имя являлся единственным источником решения проблем. Ведь большевиков изначально воспринимали не иначе, как очередных временщиков русского лихолетья. Данная точка зрения широко отражена в периодической печати конца 1917 года. Причины такого «временного положения» всегда указывались разные: от аргументов в духе рядового обывателя: «остались только Ленин и Троцкий в окружении кучки услужливой невежественной челяди» [5, с. 21], до эсхатологических объяснений вроде: «Ленин и Троцкий пытаются править Россией, но их часы сочтены...Большевики вызвали таких демонов, которых они же не в силах будут укротить» [5, с. 24]. Угли гражданской войны только начинали раздуваться, знаки будущего широкомасштабного столкновения только появлялись. Обывателей всегда заботит прежде всего собственный комфорт, а если он вдруг нарушается, то они начинают искать виноватых. Виноватыми, как правило, оказывались те, кто на виду. Обратим внимание, что го- 
рожане, в первую очередь концентрировали своё удовлетворение или недовольство указывая на первых лиц большевиков. В уже упомянутой нами газете «Правда» встречается и такое обывательское мнение, пересказываемое в ответе на критическую по отношению к большевикам статью левого мыслителя В. Базарова: «Как ни разобижен, как ни обездолен обыватель большевиками, а не может отказать им в невольной дани своего рабьего унижения» и далее идёт «усреднённая» обывательская цитата: «Хоть разбойники, а молодцы, энергичные люди, не то что те, болтуны, слюнтяи» $[14$, с. 1]. В данной цитате мы можем заметить оправдание насильственного способа решения проблем. В то же время возникла обстановка, в которой москвичи вообще переставали ориентироваться на власть. Как вспоминал офицер В.Ф. Клементьев, занимавшийся в городе подпольной антибольшевистской работой, на одной из улиц Москвы он видел классического интеллигента, продававшего газету «Эпоха», неумело выкрикивая её название. В этой газете, в частности, были размещены призывы бойкотировать все распоряжения большевиков [6, с. 43]. Уже позднее, в 1919 году, счетовод 13-й столовой Замоскворецкого района попал в лагерь на несколько месяцев за отставание в книговедении с формулировкой «считает это излишним». Из лагеря его откомандировывали для работ в той же столовой [16, Л. 82]. В целом ревизоры из районных советов зачастую отмечали, что требование ведения документов «на новый лад» подавляющим большинством просто игнорировалось.

Уже упоминавшийся нами москвич, конторский служащий пароходства «Самолёт» - Н. Окунев, так отзывался о большевиках (запись в его дневнике от 11 марта 1918 года): «Паутина их учреждений - бесчисленных советов, комиссариатов, трибуналов, коллегий, комитетов - и прочее, и прочее - всё гуще и гуще связывает российскую жизнь и становится плотной сетью, в которой мы, буржуи, беспомощно трепещемся, как рыбный лов, и чистосердечно проклинаем то, что год тому назад благословляли» [8, с. 163]. Служащих «старого образца» зачастую обвиняли в порочности новой системы на местах. О6 этом писали и в Правде за 1 января 1919 года: «Злоупотребления и волокита в Советских учреждениях скверная вещь» $[10$, с. 1]. Однако, рано или поздно это «наследие буржуазного режима» [15, с.1] будет преодолено. В таких заметках всегда имел место оптимистичный пассаж: главное, что уже есть эти рабоче-крестьянские учреждения. Да, они работают плохо, но самое главное начало положено. Да, многие служащие работают: «не за совесть, а ... ради жалованья или тех или иных материальных или правовых выгод, которые обеспечивает им советская работа» $[15$, с. 1], но это временно. Таким образом, часть новой власти воспринималась как двурушническая и приспособленческая.

В одной из заметок газеты «Правда» сообщалось о ре- акции жильцов на чрезвычайный налог. Интересная информация содержалась о людях, проживавших по адресу ул. Тверская 71. Выяснилось, что некоторые обитатели данного дома давно его покинули и не числятся в качестве жильцов, поэтому налог был резко снижен и вместо 160 тысяч, москвичи должны были заплатить 50-60 тысяч рублей: «Все ругают советскую власть, но ликуют, что так дёшево отделались» [12, с.1]. О восприятии чрезвычайного налога в Москве подробно писал Н. Окунев. Как и в других местах, люди с жалованием меньше 1500 рублей в месяц от него освобождались, но вот была незадача: в их доме числилось сразу 3 человека, которых москвич окрестил «мертвыми душами». Ситуация была идентична дому на ул. Тверская, изначально требовали сумму в 222800 рублей, а в итоге (при учете того, что подавляющее большинство жителей данного дома получали меньше 1500) получилось 19 800[8, с. 250]. Но даже такой исход вызвал смешанные чувства и такое распределение, согласно словам конторского служащего, должно быть опротестовано. В таких случаях всегда есть соблазн перейти к интерпретации данных фактов как сопротивления новой власти. Однако, как мы можем увидеть, власть активно шла навстречу москвичам, во много понимая сложившуюся ситуацию: невозможно требовать с людей денег, которых у них нет и не будет. Москвичи, в свою очередь, отвечали взаимностью: негодование было смешано с готовностью выплачивать деньги. Всё это складывается в очень неоднозначную картину: у нас представлены все точки зрения: от поддержки новой власти до попыток прямого или косвенного сопротивления. Безусловно, стоило ожидать, что люди резко потерявшие свой былой социальный статус вроде москвича Н. Окунева, были недовольны своим новым положением и совершенно справедливо увязывали данный факт с новой властью. С другой стороны, у нас присутствует типичное одобрение власти, так как обыватель замечает её активную деятельность.

В обществе в целом наметилась общая тенденция на политическую апатию или, что будет точнее, адаптивность. Уже указанный член ревизионной комиссии И.Б. Эльяшевич, всё в той же чайной номер 23 Замоскворецкого района столкнулся со следующим курьёзом. Официальных отчётных книг нет, а заведующий помещением товарищ Емельянов исполнял обязанности практически всего персонала (даже повара). Когда ревизор начал смотреть «неофициальную документацию» то обнаружил, что записи там примерно следующего характера: тов. Емельянов просит тов. Емельянова выдать тов. Емельянову разные продукты [17, Л. 27]. Таким образом, человек «как мог» исполнял требования новых властей. Люди фокусировались скорее на решении ежедневных проблем, пытаясь найти для себя внутренний компромисс. М. Горький, который в указанный период занимался общественной работой, в том числе организовал Комитет по улучшению быта учёных, в выдаваемом им 
пайке прилагал, кроме всего прочего, плитку шоколада. Над этим как-то посмеялся художник Ю.П. Анненков, на что Горький ответил: «Все люди немного дети, и в седобородом ученом сидит ребёнок. Революция их сильно обидела. Нужно им дать по шоколадке, это многих примирит с действительностью и внутренне поддержит» [2, с. 11]. Для каждого москвича эта «примиренческая шоколадка» была своя. Для клерка Н. Окунева - это возможность запастись дровами на зиму, предоставленная Рупводом (они с коллегами разбивали на берегу песочную шаланду по принципу: половина дров себе, половина учреждению, по ироничному замечанию москвича - «барщина своего рода») [8, с. 294]. Для простых рабочих - это начавшаяся кипучая деятельность по переустройству общества с целью максимального улучшения их собственного быта. Для женщин - ускорившаяся феминизация различных учреждений. Для «бывших» купцов, речь одного из которых передаёт В.В. Шульгин, таким фактом являлось уважение его убеждений, возможность соблюдать посты, ходить в церковь и молиться: «А мои какие убеждения? Религиозные. Коммунизм - коммунизмом, а религия - религией...Они смеются, но не препятствуют» [18, с. 209]. Разговор этот, правда, случился уже в период НЭПа, однако вспоминал купец о временах ещё «начала революции» и такое отношение существенно примиряло людей с новой властью. Большевики в какой-то момент начинают просто выступать неким фоном всеобщей разрухи. Новые органы управления и новые законы москвичам надоедают, рефлексирующий на страницах своего дневника Н. Окунев вопрошал: что отмечать в 1918 году? Было очень много декретов, постановлений, возникли новые республики, но разве это предел? Москвич предвосхищает, что и в 1919 году они будут «сыпаться на нас как из рога изобилия» [8, с. 251]. Это и являлось одной из главных черт восприятия большевиков - кипучая и бурная деятельность по переустройству жизни. Безусловно, большевики резко вмешивались и в частную жизнь горожан, иными словами то, что мы можем назвать свободным временем. Это заключалось, в первую очередь, в принудительном участии в различных митингах и собраниях: «Бежишь домой, целый день не евший, а хвать входные двери на запоре и у них строгая охраняющая вход личность» [8, с. 253].

С другой стороны, у нас есть случаи, когда произвол на районном уровне карался. Некий гражданин Белов владел гробовой мастерской в Замоскворецком районе Москвы. В ходе ревизии выяснилось, что москвич все расчёты проводил устно, расчётных книжек не было $[16$, л. 86]. Однако посетившие его с ревизией представители власти изъяли также гробовые доски используя для этого странный предлог: «доски для изготовления гробов не употреблялись» [16. Л. 88]. Члены инспекции, изъявшей доски, в частности граждане Хлоплянкин, Богомолов, Ротшильд и Ватковский, были вызваны в суд за эту незаконную реквизицию. Их признали виновными в превышении полномочий и приговорили к работам на 6 месяцев без лишения свободы. Особенно в данном решении отмечалось, что они своими действиями дискредитируют власть вообще, создавая ложное представление о ней в массах [16, Л. 95].

Безусловно, такие вещи порождали логичную ответную реакцию, которая проявлялась в попытках поиска справедливости. Любопытной является одна из жалоб, поданная на имя В.Д. Бонч-Бруевича в апреле 1919 года, в которой автор А.В Дебор в прямом смысле вопрошает: кому или куда можно жаловаться? [9, с. 105]. Само письмо содержит инициативу, суть которой заключается в создании такого учреждения, окрещённого самим автором "Комиссариат по жалобам и заявлениям". Обратим внимание на то, что автор обращения использует революционный язык вполне осмысленно. Сама по себе жалоба любопытна, потому что её автор делает особый акцент на "поиске правды", так как человек в условиях социального хаоса зачастую попадает в ситуации, когда каждый отвечает сам за себя. Текст письма содержит и очевидный "наскок" на власть, содержащийся во мнении: жаловаться, кроме ЧК - некуда (и то есть определённый риск из обвиняющего превратится в обвиняемого [9, с. 105]), в суде дело пролежит "до второго пришествия", отсюда и закономерный вопрос для обывателя "у кого искать справедливость?" [9, с. 105]. Любопытно, что в жалобе упоминается некий ящик, который разместили на Красной площади и куда мог закинуть прошение любой желающий. Однако, по информации всё того же Дебора этот ящик вскоре исчез после того, как в нём «начали появляться пасквили» [9, с. 105]. Существовал ли этот ящик в реальности не так важно: в представлении горожанина он исчез, как только в нём начала появляться критика власти. Таким образом, здесь прослеживается намёк на нежелание властей обращать своё внимание на проблемные стороны жизни. Как мы можем увидеть из одного только этого обращения - москвичи искали защиты у сильных мира сего.

Другой пример - письмо на имя В.И. Ленина от служащего К. Антонова, который в январе 1920 года нарисовал следующую картину. В Новый год на всех «столовках» была одна и та же надпись: закрыто [9, с. 147]. Москвич ярко передаёт реакцию людей на происходящее: «Когда же кончится эта проклятая жизнь», «вертишься, как в мясорубке», «о людях у них заботушки мало, сами, небось, по горло сыты» и так далее до бесконечности, - слышатся эти выкрики голодных озлобленных людей» [9, с. 147]. Злоба людская продиктована голодом и во многом обманутыми обещаниями. Для К. Антонова, который с его слов работает счетоводом, большевики сыграли на людских страстях, сам В. Ленин позиционирующий себя не иначе как «благодетель бедноты» [9, с. 148] оторван от реальности, ему буквально предлагается побродить по городским улицам и увидеть «настоящую жизнь». Из 
данного послания рисуется восприятие обывателями большевистской власти как «сытой», очередной «группы хищников», которая сменила своих предшественников [9, с. 148]. Можно сказать, что это - крик души человека, поставленного в трудные жизненные обстоятельства, в данном письме основной упор идёт на недоедание как автора, так и его жены. Как и другого служащего - Н. Окунева, К. Антонова беспокоят не только цены, но и качество товаров, в частности, продуктов.

Упомянутый нами офицер В. Клементьев писал: «В трамвае я подхватил место у окна и неотрывно смотрел на москвичей, торопливо двигавшихся по тротуарам, по мостовым. Я им завидовал. Они ни в каких антибольшевицких организациях не участвуют, а живут своей повседневной жизнью» [6, с. 136]. Безусловно, воспоминания офицера наполнены пессимизмом, однако наблюдение за тем, что обыватель оставался обывателем, в целом, верное. Наиболее детальный в этом плане источник - дневник москвича Н. Окунева практически каждый день сообщает нам о ценах на различные товары. «Купил сегодня себе шерстяную фуфайку за 200 рублей, все завидуют, говорят - страшно дёшево» [8, с.248] - писал он в декабре 1918 года.

Вот следующий пример - очередное письмо на имя В.И. Ленина, в котором оставшийся анонимным обыватель вопрошает: «Что творится на Руси?». Его месячное жалование служащего в районе 1500-2000 рублей, а цены на чёрном рынке позволяют жить при такой зарплате 3-4 дня, остаётся неясным: что делать остальные 27 дней? [9, с. 149] Данное письмо едва ли можно назвать жалобой, это очередной пример эмоционального всплеска. Большевики обвиняются не только в том, что жизнь существенно ухудшилась, но и в бездействии: «Декреты пекутся ежедневно, а пользы - ни на волос» [9, с. 149]. Как было указано выше - сама большевистская печать нередко критиковала органы местной власти, обыватели в данном случае лишь констатировали уже известные факты. Данное письмо завершается словами: «Дело надо делать, а не на бумаге сулить два года» [9, с. 149]. Такое восприятие власти и властных лиц, как людей, пускающих пыль в глаза, энергичных в каком-то смысле, но неэффективных, было характерно и для людей из высшего общества. В своих воспоминаниях русский театральный деятель С. Волконский так охарактеризовал речь Луна- чарского: «...как всегда длинную, как всегда пересыпанную цитатами, бесчисленным количеством иностранных слов» [4, с. 361]. Здесь опять видно, что нарком просвещения воспринимается как человек, возможно и умный, потративший на свою речь немало времени, но итог её производил другое впечатление - «пересыпанное», слов сказано много - а сути мало: «Но таков уж прием этих людей: они всегда говорили об идеях, никогда о фактах или действиях» [4, с. 362].

Таким образом на примере указанных источников мы можем прийти к нескольким приблизительным выводам. Для горожан, поставленных в непростые условия, восприятие власти напрямую соотносилось с сытым желудком. В тоже время сам факт обращений на имя В.И. Ленина или В.Д. Бонч-Бруевича свидетельствовал о том, что жители города верили в реальность разрешения проблем, если написать «на самый верх». Существование некоего человека, на котором замыкается принятие решений по разным вопросам характерно не только для этой эпохи. Однако важно отметить, что вместе с широко распространённой в сознании людей идеи об отсутствии (или незначительности) власти, существовала и идея о власти вполне реальной, которая решает проблемы, пускай и чрезвычайными методами. Слух или же реальный факт про «ящик на Красной площади» очередное свидетельство тому, что поиск справедливости может увенчаться успехом. Разделение москвичей чётко прослеживается в том, что каждый был занят своими собственными проблемами. Невероятно сложное, в том числе и в психоэмоциональном плане, время порождало и такое же сложное восприятие власти. Исследователь В.Б. Аксёнов также объясняет принятие власти большевиков феноменом запроса на постправду - т.е. желанием быть обманутым, ради достижения временного психологического комфорта [1, с. 918]. Избыточное эмоциональное напряжение с начала Первой мировой и в течении всего 1917 года своим итогом имело либо полную опустошённость, либо душевные расстройства у населения. Осознание горожанами факта «что хуже быть может», который ярко отражался, в частности, в недостатках топлива и ухудшением качества пищи, приводило их к некоторому смирению с окружающей действительностью. Власть же, где могла - шла на уступки, стараясь в то же время заботиться о собственном имидже.

\section{ЛИТЕРАТУРА}

1. Аксёнов В.Б. Массовые настроения россиян в годы войны и революции: 1914-1918. М.: НЛО, 2020. - 992 С.

2. Анненков Ю.П. Дневник моих встреч. М.: Захаров, 2001. - 514 с.

3. Бергер П, Лукман Т. Социальное конструирование реальности. М.: Медиум, $1995-336$ с.

4. Волконский С.М. Родина: Воспоминания. М.; Берлин: Директ-медиа. 2016. - 475 с.

5. Гражданская война день за днём / Сост. В.С. Черепенчук. СПб.: РХГА, 2018. - 468 с. 
6. Клементьев В.Ф. В большевицкой Москве (1918-1920 гг.). М.: Русский путь, 1998. - 448 с.

7. Неизвестная Россия XX век. В 2-х книгах. Книга 2. / Под ред. В.А. Козлова. М.: Историческое наследие, 1992. - 386 с.

8. Окунев Н.П. Дневник москвича, 1917-1924. В 2 т. Т.1. М.: Военное издательство, 1997. - 320 с.

9. Письма во власть. 1917-1927. Заявления, жалобы, доносы, письма в государственные структуры и большевистским вождям / Сост. А.Я. Лившин, И.Б. Орлов. М.: РОССПЭН, 1998. - 664 с.

10. Правда, №1, 1 января 1919.

11. Правда, №2, 3 января 1919.

12. Правда, №7, 12 января 1919.

13. Правда, № 47, 12 марта 1918 г.

14. Правда, №49, 15 марта 1918 г.

15. Труды Центрального Статистического управления. Том VIII. Выпуск 1. Статистический ежегодник 1918-1920 гг. М., 1921. - 691 с.

16. ЦГАМ. Ф.Р-1616. Оп.3. Д.29.

17. ЦГАМ. Ф.Р-1616. Оп.3. Д.54.

18. Шульгин В.В. Три столицы. М: Современник, $1991-496$ с.

19. Эпоха социалистической реконструкции : идеи, мифы и программы социальных преобразований : сб. науч. тр. / гл. редактор Л.Н. Мазур. Екатеринбург: Изд-во Урал. ун-та, 2017. - 752 с.

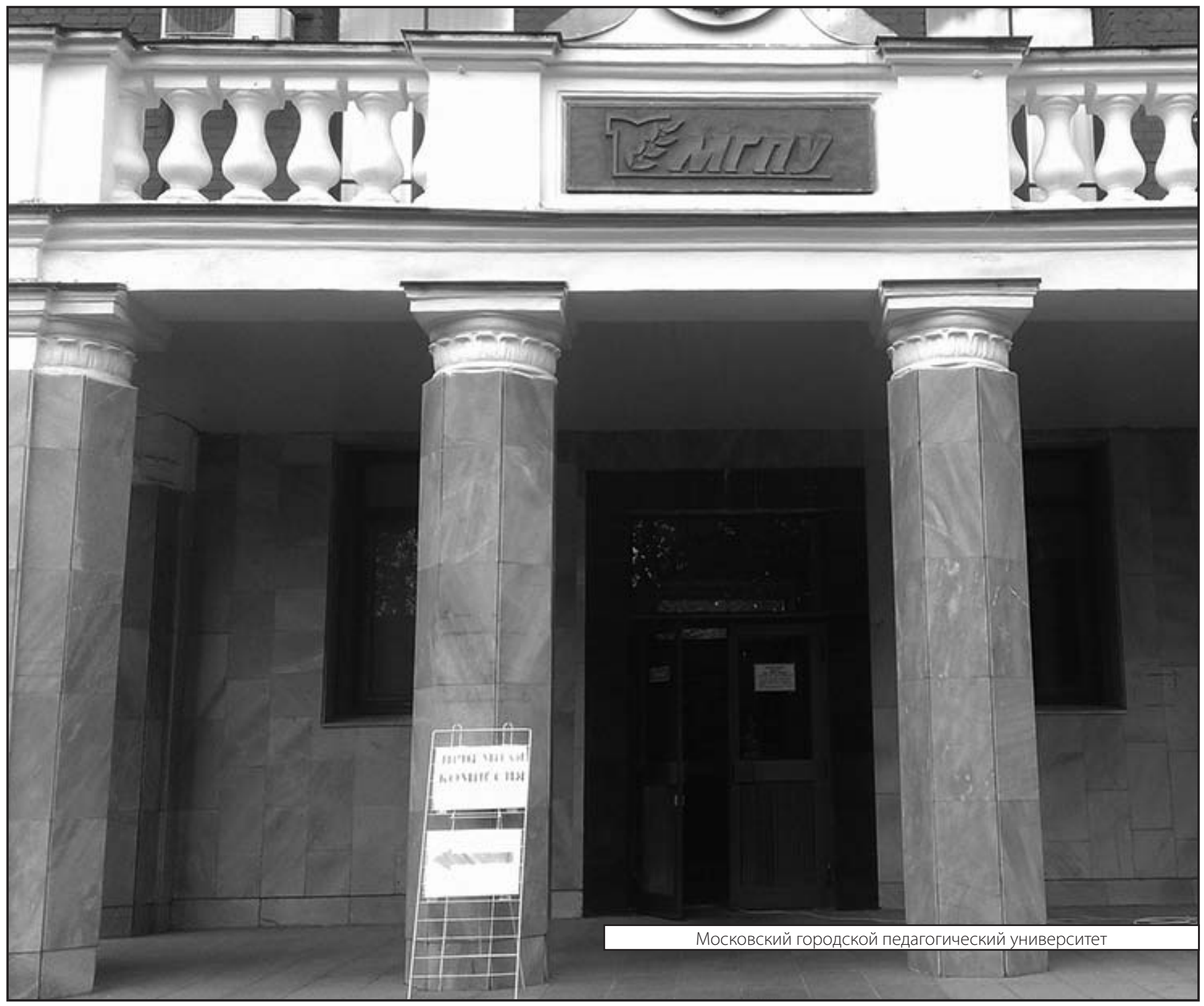

